\title{
Proton pump inhibitor on susceptibility to COVID-19 and its severity: a systematic review and meta-analysis
}

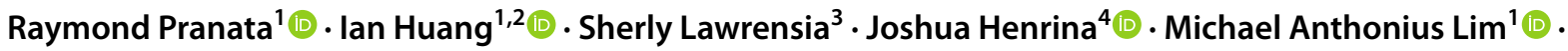 \\ Antonia Anna Lukito ${ }^{5}$ Raden Ayu Tuty Kuswardhani ${ }^{6} \cdot$ I. Dewa Nyoman Wibawa $^{7}$
}

Received: 25 January 2021 / Revised: 10 March 2021 / Accepted: 2 April 2021 / Published online: 11 April 2021

(c) Maj Institute of Pharmacology Polish Academy of Sciences 2021

\begin{abstract}
Background The negative impacts of proton pump inhibitor (PPI), including the risk of pneumonia and mortality, have been reported previously. This meta-analysis aimed to address the current interest of whether the administration of PPI could increase the susceptibility and risk of poor outcome in COVID-19.

Methods We performed a systematic literature search from PubMed, Embase, EBSCOhost, and EuropePMC databases up until 3 December 2020. The main outcome was composite poor outcome which comprised of mortality and severe COVID19. Severe COVID-19 in this study was defined as patients with COVID-19 that fulfill the criteria for severe CAP, including the need for intensive unit care or mechanical ventilation. The secondary outcome was susceptibility, based on cohort comparing COVID-19 positive and COVID-19 negative participants.

Results There were a total of 290,455 patients from 12 studies in this meta-analysis. PPI use was associated with increased composite poor outcome (OR 1.85 [1.13, 3.03], $p=0.014 ; I^{2} 90.26 \%$ ). Meta-regression analysis indicate that the association does not vary by age (OR $0.97[0.92,1.02], p=0.244)$, male (OR $1.05[0.99,1.11], p=0.091)$, hypertension (OR 9.98 [0.95, 1.02], $p=0.317$ ), diabetes (OR 0.99 [0.93, 1.05], $p=0.699$ ), chronic kidney disease (OR 1.01 [0.93, 1.10], $p=0.756$ ), nonsteroidal anti-inflammatory drug use (OR 1.02 [0.96, 1.09], $p=0.499)$, and pre-admission/in-hospital PPI use (OR 0.77 [0.26, $2.31], p=0.644$ ). PPI use was not associated with the susceptibility to COVID-19 (OR $1.56[0.48,5.05], p=0.46 ; I^{2} 99.7 \%$ ). Conclusion This meta-analysis showed a potential association between PPI use and composite poor outcome, but not susceptibility.
\end{abstract}

PROSPERO ID: CRD42020224286.

Keywords Proton pump inhibitor · Coronavirus · Severity $\cdot$ Infection rate $\cdot$ Susceptibility $\cdot$ Gastrointestinal

Antonia Anna Lukito

Antonia.lukito@uph.edu; lukito_ant@yahoo.com;

lukito@uph.edu

Raymond Pranata

raymond_pranata@hotmail.com

Ian Huang

ianhuang2108@gmail.com

Sherly Lawrensia

sherlylawrensia@gmail.com

Joshua Henrina

joshuahenrina@gmail.com

Michael Anthonius Lim

lim.michael.a@gmail.com

Raden Ayu Tuty Kuswardhani

tutykuswardhani@unud.ac.id; tutykuswardhani@yahoo.com

I. Dewa Nyoman Wibawa

dnwib.dps@centrin.net.id
1 Faculty of Medicine, Universitas Pelita Harapan, Tangerang, Indonesia

2 Department of Internal Medicine, Faculty of Medicine, Universitas Padjadjaran, Hasan Sadikin General Hospital, Bandung, Indonesia

3 Ken Saras General Hospital, Semarang, Indonesia

4 Balaraja General Hospital, Tangerang, Indonesia

5 Department of Cardiology and Vascular Medicine, Siloam Hospitals Lippo Village, Tangerang, Indonesia

6 Department of Internal Medicine, Faculty of Medicine, Udayana University, Sanglah Teaching Hospital, Denpasar- Bali, Indonesia

7 Division of Gastroentero-Hepatology, Department of Internal Medicine, Faculty of Medicine, University of Udayana, Denpasar, Indonesia 


\section{Introduction}

The COVID-19 pandemic is undeniably on its highest spike all over the globe. On the advent of effective SARS-CoV-2 vaccination, many believe that this pandemic may finally be over. However, there is still a relatively wide gap of time before the 'mass' vaccination could finally be accomplished. In that meantime, we still need to take some extra precautions in preventing COVID-19 infection and its fatal complications by identifying factors associated with COVID-19 susceptibility and severity [1,2].

Proton pump inhibitors (PPI) have been commonly prescribed for the management of gastrointestinal (GI) acidrelated disorders, including peptic ulcer disease and gastroesophageal reflux disease (GERD) [3]. Many patients taking non-steroidal anti-inflammatory drugs (NSAIDs) and/or corticosteroids routinely for their chronic pain or illness are also consuming PPI as stomach-protective agents. However, PPI is also frequently prescribed without a clear indication in up to $70 \%$ of cases [4]. Without proper indication and guidance, the use of such drugs may be harmful for the patients and may cause unwanted side effects.

The negative impacts of PPI, including the risk of pneumonia and mortality, have been reported previously [5-7]. Furthermore, PPI administration increased the risk of both enteric infections and small intestinal bacterial overgrowth, while the risk of enteric viral infection during high endemic periods is also increased with continued use of PPI [8-10]. Whether the use of PPI increases susceptibility to SARS-CoV-2 infection is still unknown, but current PPI usage is potentially associated with increasing severity and worsening outcomes in COVID19 [3]. A study observed that individuals taking PPI twice daily are almost four times more likely to report a positive COVID-19 test when compared to those not on PPI [11].

This meta-analysis aimed to address the current interest of whether the administration of PPI could increase the susceptibility and risk of poor outcome in COVID-19.

\section{Methods}

\section{Protocol and registration}

This study is following the Preferred Reporting Items for Systematic Reviews and Meta-Analyses (PRISMA) reporting guidelines. The protocol for this study is registered in PROSPERO (CRD42020224286).

\section{Inclusion and exclusion criteria}

The inclusion criteria were: (1) prospective or retrospective observational studies reporting confirmed COVID-19 patients and (2) reporting mortality or severity based on PPI use OR reporting COVID-19 infection rate based on PPI use. The main outcome was composite poor outcome which comprised of mortality and severe COVID-19. Mortality was defined as clinically validated death/mortality/non-survivor. Severe COVID-19 in this study was defined as patients with COVID-19 that fulfill the criteria for severe CAP, including the need for intensive unit care or mechanical ventilation [12]. The secondary outcome was susceptibility, based on cohort comparing COVID-19 positive and COVID-19 negative participants.

The exclusion criteria were: (1) preprints, (2) nonresearch letters, (3) review articles, (4) commentaries, (5) case reports or series, and (6) non-English Language articles.

\section{Search strategy and study selection}

Systematic literature searches of PubMed, Embase, EBSCOhost, and EuropePMC databases were performed with keywords (COVID-19 OR SARS-CoV-2 OR 2019-nCoV) AND (Proton Pump Inhibitors OR PPIs) AND (Mortality OR Severity OR ICU Admission OR Mechanical Ventilation OR Intubation OR Susceptibility OR COVID-19 Positive) from inception up until 9 December 2020. Additionally, snowballing technique by hand-picking relevant articles from references of the included studies were performed. Two independent authors performed screening of the title and abstract of the records after removal of duplicates. The fulltext of potentially eligible articles were assessed based on the inclusion and exclusion criteria.

\section{Data extraction}

Two authors independently perform data extraction from eligible studies for the first author, year of publication, study design, age, male (gender), hypertension, diabetes, chronic kidney disease (CKD), NSAID use, PPI use, and the outcome of interest.

The main outcome was composite poor outcome and the secondary outcome was susceptibility; the effect estimates were reported in odds ratios (ORs) and its $95 \%$ confidence interval.

The key exposure for composite poor outcome was PPI use, defined as current use of PPI prior to admission (routine medication) or in-hospital use, for any reason. The key exposure for susceptibility was PPI use, defined as current use of PPI prior to admission (routine medication), for any reason.

\section{Risk of bias assessment}

Quality assessment of the included studies were performed by two independent authors using the Newcastle-Ottawa 
Scale (NOS). Discrepancies that arises during the assessment were resolved by discussion.

\section{Statistical analysis}

STATA 16 (StataCorp LLC, Texas, US) was used to perform statistical analysis of the extracted data. The ORs for composite poor outcome and susceptibility were pooled using the restricted maximum likelihood (REML) random-effects model, regardless of heterogeneity, and reported as OR and its $95 \%$ CI. $p$ values of the pooled effect estimate were considered significant if the value was $\leq 0.05$. Inter-study heterogeneity was assessed using $I$-squared $\left(I^{2}\right)$ and Cochrane $Q$ test; in which a value of $>50 \%$ or $p$ value $<0.10$ indicates significant heterogeneity. Funnel-plot analysis and Egger's test were performed to evaluate the risk of publication bias qualitative and quantitatively. Trim-and-fill analysis using the Run 0 estimator was performed to add hypothetical study based on possible publication bias. REML meta-regression analysis was performed for the age, gender, hypertension, diabetes, CKD, NSAIDs, and pre-admission/in-hospital PPI use as covariate, one at a time.

\section{Results}

\section{Baseline characteristics and study selection}

There were a total of 290,455 patients from 12 studies included in this systematic review and meta-analysis $[3,11$, 13-23] (Fig. 1). 11,508 patients were available for analysis on composite poor outcome and 283,732 patients were available for analysis on susceptibility. Baseline characteristics of the included studies was displayed in Table 1.

\section{Proton pump inhibitor and composite poor outcome}

PPI use was associated with increased composite poor outcome (OR 1.85 [1.13, 3.03], $p=0.014 ; I^{2} 90.26 \%$, $p<0.001$ ) (Fig. 2). Meta-regression analysis indicate that

Fig. 1 PRISMA flowchart

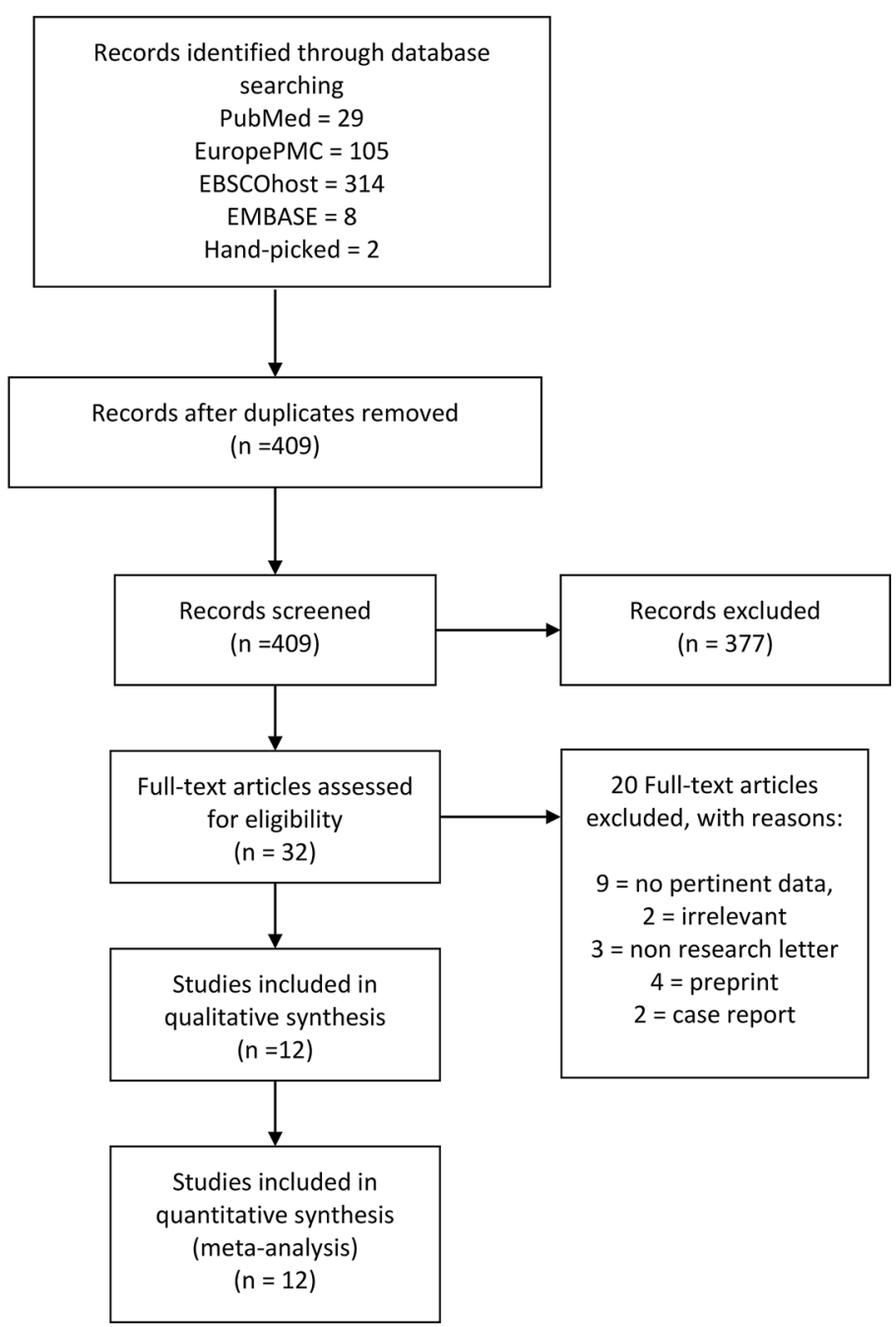




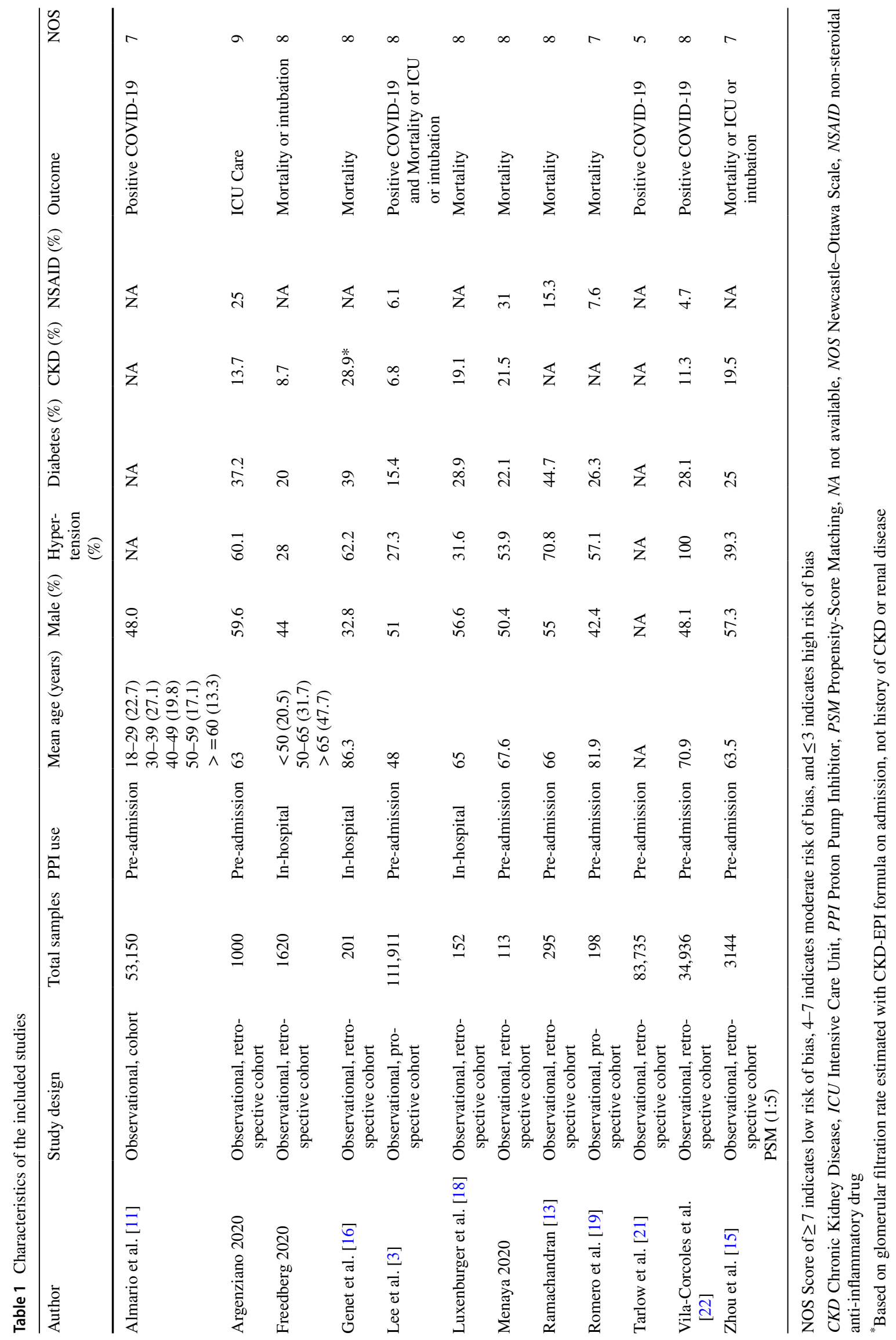


the association does not vary by age (OR 0.97 [0.92, 1.02], $p=0.244)$, male (OR $1.05[0.99,1.11], p=0.091)$, hypertension (OR 9.98 [0.95, 1.02], $p=0.317$ ), diabetes (OR 0.99 [0.93, 1.05], $p=0.699)$, CKD (OR $1.01[0.93,1.10]$, $p=0.756$ ), NSAID use (OR 1.02 [0.96, 1.09], $p=0.499$ ), and pre-admission/in-hospital PPI use (OR 0.77 [0.26, 2.31], $p=0.644)$.

\section{Proton pump inhibitor and susceptibility to COVID-19}

PPI use was not associated with the susceptibility to COVID19 (OR $1.56[0.48,5.05], p=0.46 ; I^{2} 99.7 \%, p<0.001$ ) (Fig. 3).

\section{Publication bias}

The pooled analysis for PPI and composite poor outcome has asymmetrical funnel plot (Fig. 4), trim-and-fill analysis by run 0 estimator did not result in addition of hypothetical study on the left or right side. Egger's test was not significant for small-study effect $(p=0.699)$.

\section{Discussion}

This meta-analysis showed a potential association between PPI use and composite poor outcome. The association did not vary with age, gender, hypertension, diabetes, and NSAID use; based on meta-regression of limited studies. However, there is a potential publication bias that may render the association non-significant. PPI was not associated with increased susceptibility to COVID-19.

Alternatively, there are potential confounders that may contribute to the association. This includes the need for PPI use on certain disease or concurrent use with certain medications. The disease itself might contribute significantly to COVID-19 severity and mortality. Although meta-regression
Fig. 2 Proton pump inhibitor and composite poor outcome. The diamond-shaped structure represents the pooled effect estimate. $I^{2} I$-squared
Fig. 3 Proton pump inhibitor and susceptibility to COVID-19. The diamond-shaped structure represents the pooled effect estimate. $I^{2} I$-squared

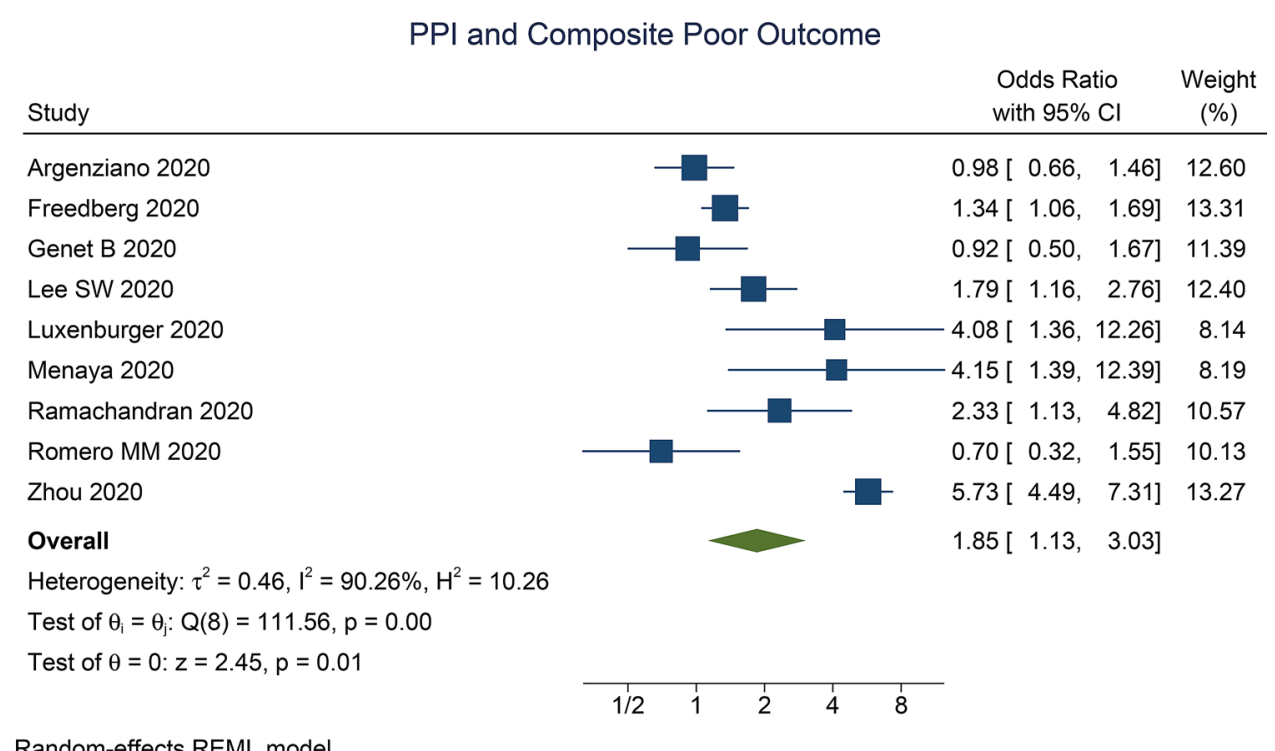

Random-effects REML model 
Fig. 4 Funnel-plot analysis. $\mathrm{X}$-axis represent the effect size (log odds ratio) and Y-axis represent the standard error. The reference (red) effect-size line indicates the estimated $\theta I V$

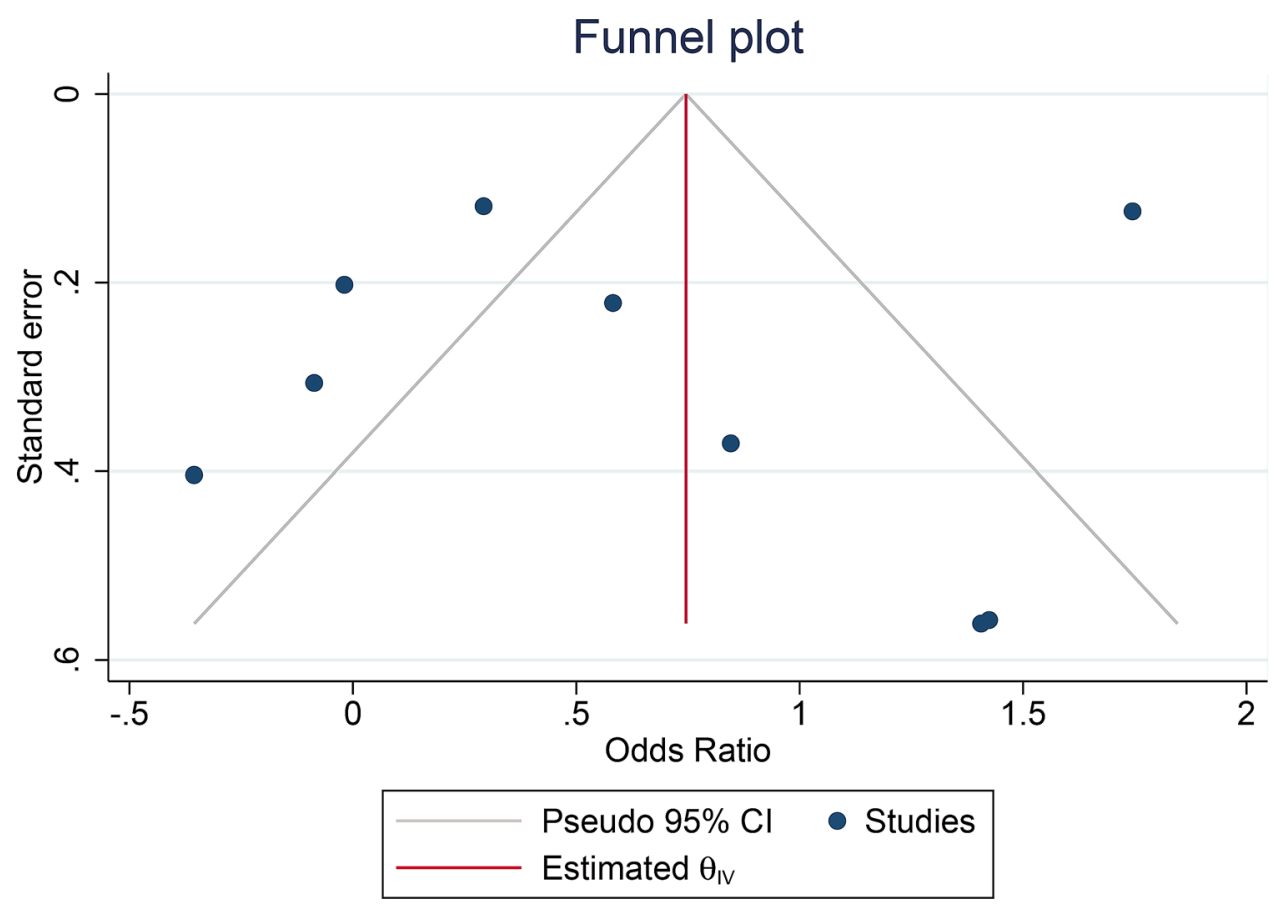

analysis did not show a significant variation of effect estimate relative to the NSAID use, the regression (for the NSAID use) was only based on five studies. A minimum of ten studies is required to obtain an accurate result. Metaregression analysis in this study was only aimed to ruling in any association, not ruling them out. Certain medications such as angiotensin-receptor blocker and metformin was also shown to be associated with reduced severity [24, 25]; although publication bias is very likely.

There was a potential publication bias among the included studies as indicated by the asymmetrical funnel plot. Choices of databases were PubMed (MEDLINE), Embase, EBSCOhost, and EuropePMC which yielded broad results. Based on AMSTAR-2, there should be at least two databases [26]. Bramer et al. proposed that Embase, MEDLINE, Web of Science (Core Collection), and Google Scholar were optimal databases for conducting systematic review [27]. Their study did not account for EuropePMC, which usually provides broad results. The use of Google Scholar was controversial because of poor search reproducibility [28] and we decided to use EuropePMC instead. These measures have been taken to limit the publication bias.

Vila-Corcoles et al. [22] showed that PPI was associated with susceptibility to COVID-19 on unadjusted but not adjusted analysis, indicating that the increased susceptibility might be due to other confounding variables. Vila-Corcoles et al. noted that age was the only independent predictor for COVID-19 infection. An independent dose-response relationship was observed by Almario et al., in which twicedaily PPI has a higher risk for COVID-19 compared to once daily PPI [11]. Almario et al. conducted an online survey and the authors acknowledge the possibility of selection bias, the respondents are more likely to be young or elderly respondents with better function. Thus the adjustment might be inadequate, which leads to overestimation of the effect estimate.

The association between PPI administration with the increase of susceptibility and severity of SARS-CoV-2 infection is biologically plausible. Gastric juice is the first line of defense against pathogens, including bacteria and viruses, with one of the main functions of eradicating ingested pathogens and thereby inhibiting infectious microorganisms from reaching the intestine [4]. The normal $\mathrm{pH}$ of a healthy stomach $(\leq 3)$ disrupts the infectivity of the similar SARS-CoV-1, whereas less acidic pH due to PPI-induced gastric acid suppression does not deactivate the virus [29]. The ACE2 receptors, which are also widely expressed throughout the intestinal tract [30], are used by SARS-CoV-2 to quickly invade and replicate within enterocytes [31]. Consequently, gastritis, enteritis, and colitis are pathologically and clinically evident [32]. Moreover, increasing viral loads enables the virus to propagate beyond the digestive system by causing GI symptoms and disseminating infection or inducing inflammation in the lungs via a gut-lung axis or other organs via cytokine release syndrome [11]. PPI treatment may promote the development of pneumonia due to suppressed gastric acid production, which results in increased gastric microbiota, bacterial overgrowth in the upper GI tract, and micro-aspiration leading to bacterial colonization of the lung [33]. In addition, PPI may also dampen immune response 
by inhibiting anti-inflammatory function of neutrophil [34]. Therefore, PPI usage could also be a potential risk factor for the development of secondary infections and consecutive ARDS in hospitalized COVID-19 patients [4, 18].

Theoretically, the risk of poor outcome in COVID-19 patients receiving PPI might be due to kidney injury. As previously reported by Xie et al. [5], PPI use was associated with the risk of mortality due to CKD. Several studies have documented its use with an increased risk of acute kidney injury (AKI), CKD, and CKD progression to end-stage kidney disease [35-37]. Moreover, our previous meta-analysis showed that the presence of either AKI or CKD is associated with an increased risk of poor outcome in patients with COVID-19 [38-40]. However, meta-regression did not reveal any association between the risk of poor outcome and the use of PPIs.

\section{Limitations}

Limitation of this systematic review includes the publication bias, in which study with positive result is more likely to be published, indicated by the asymmetrical funnel plot. However, trim-and-fill analysis did not result in imputation of hypothetical study. Various hidden confounders may affect the effect estimate. Meta-regression analysis was based on a limited number of studies; thus, the regression analysis's statistical power is weak.

\section{Conclusion}

This meta-analysis showed a potential association between PPI use and composite poor outcome, but not susceptibility.

\begin{abstract}
Author contributions RP: conceptualization, data curation, formal analysis, investigation, methodology, validation, writing-original draft. IH: data curation, investigation, methodology, validation, writing-original draft. SL: data curation, investigation, writing-original draft. JH: data curation, investigation, writing - review and editing. MAL: investigation, writing — original draft. AAL: investigation, writing-review and editing. RATK: investigation, writing-review and editing. IDNW: investigation, writing —review and editing.
\end{abstract}

Funding None.

Data availability Data are available on reasonable request.

\section{Declarations}

Conflict of interest The authors declare that they have no conflict of interest.

\section{References}

1. Pranata R, Lim MA, Yonas E, Vania R, Lukito AA, Siswanto BB, et al. Body mass index and outcome in patients with COVID-19: a dose-response meta-analysis. Diabetes Metab. 2020. https://doi. org/10.1016/j.diabet.2020.07.005.

2. Yonas E, Alwi I, Pranata R, Huang I, Lim MA, Gutierrez EJ, et al. Effect of heart failure on the outcome of COVID-19-a meta analysis and systematic review. Am J Emerg Med. 2020. https:// doi.org/10.1016/j.ajem.2020.07.009.

3. Lee SW, Ha EK, Yeniova AÖ, Moon SY, Kim SY, Koh HY, et al. Severe clinical outcomes of COVID-19 associated with proton pump inhibitors: a nationwide cohort study with propensity score matching. Gut. 2021;70:76-84. https://doi.org/10.1136/ gutjnl-2020-322248.

4. Charpiat B, Bleyzac N, Tod M. Proton pump inhibitors are risk factors for viral infections: even for COVID-19? Clin Drug Investig. 2020;40:897-9. https://doi.org/10.1007/s40261-020-00963-x.

5. Xie Y, Bowe B, Yan Y, Xian H, Li T, Al-Aly Z. Estimates of all cause mortality and cause specific mortality associated with proton pump inhibitors among US veterans: Cohort study. BMJ. 2019;365:11580. https://doi.org/10.1136/bmj.11580.

6. Bateman BT, Bykov K, Choudhry NK, Schneeweiss S, Gagne JJ, Polinski JM, et al. Type of stress ulcer prophylaxis and risk of nosocomial pneumonia in cardiac surgical patients: Cohort study. BMJ. 2013;347:f5416-f5416. https://doi.org/10.1136/bmj.f5416.

7. Eom CS, Jeon CY, Lim JW, Cho EG, Park SM, Lee KS. Use of acid-suppressive drugs and risk of pneumonia: a systematic review and meta-analysis. CMAJ. 2011;183:310-9. https://doi. org/10.1503/cmaj.092129.

8. Lo WK, Chan WW. Proton pump inhibitor use and the risk of small intestinal bacterial overgrowth: a meta-analysis. Clin Gastroenterol Hepatol. 2013;11:483-90. https://doi.org/10.1016/j.cgh. 2012.12.011.

9. Leonard J, Marshall JK, Moayyedi P. Systematic review of the risk of enteric infection in patients taking acid suppression. Am J Gastroenterol. 2007;102:2047-56. https://doi.org/10.1111/j.15720241.2007.01275.x

10. Bavishi C, DuPont HL. Systematic review: the use of proton pump inhibitors and increased susceptibility to enteric infection. Aliment Pharmacol Ther. 2011;34:1269-81. https://doi.org/10. 1111/j.1365-2036.2011.04874.x.

11. Almario CV, Chey WD, Spiegel BMR. Increased risk of COVID19 among users of proton pump inhibitors. Am J Gastroenterol. 2020;115:1707-15. https://doi.org/10.14309/ajg.0000000000 000798.

12. Metlay JP, Waterer GW, Long AC, Anzueto A, Brozek J, Crothers K, et al. Diagnosis and treatment of adults with communityacquired pneumonia. Am J Respir Crit Care Med. 2019;200:E4567. https://doi.org/10.1164/rccm.201908-1581ST.

13. Ramachandran P, Perisetti A, Gajendran M, Jean-Louis F, Bansal $\mathrm{P}$, Dwivedi AK, et al. Pre-hospitalization proton pump inhibitor use and clinical outcomes in COVID-19. Eur J Gastroenterol Hepatol. 2020. https://doi.org/10.1097/meg.0000000000002013 (Publish Ah:2020.07.12.20151084).

14. Vinet L, Zhedanov A. A "missing" family of classical orthogonal polynomials. J Phys A Math Theor. 2011;44(1129-1131):e3. https://doi.org/10.1088/1751-8113/44/8/085201.

15. Zhou J, Wang X, Lee S, Wu WKK, Cheung BMY, Zhang Q, et al. Proton pump inhibitor or famotidine use and severe COVID-19 disease: a propensity score-matched territory-wide study. Gut. 2020. https://doi.org/10.1136/gutjnl-2020-323668.

16. Genet B, Vidal JS, Cohen A, Boully C, Beunardeau M, Marine Harlé L, et al. COVID-19 in-hospital mortality and use of reninangiotensin system blockers in geriatrics patients. J Am Med Dir 
Assoc. 2020;21:1539-45. https://doi.org/10.1016/j.jamda.2020. 09.004 .

17. Hao B, Sotudian S, Wang T, Xu T, Hu Y, Gaitanidis A, et al. Early prediction of level-of-care requirements in patients with COVID19. Elife. 2020;9:1-23. https://doi.org/10.7554/eLife.60519.

18. Luxenburger H, Sturm L, Biever P, Rieg S, Duerschmied D, Schultheiss M, et al. Treatment with proton pump inhibitors increases the risk of secondary infections and ARDS in hospitalized patients with COVID-19: coincidence or underestimated risk factor? J Intern Med. 2021;289:121-4. https://doi.org/10.1111/ joim. 13121.

19. Mas Romero M, Avendaño Céspedes A, Tabernero Sahuquillo MT, Cortés Zamora EB, Gómez Ballesteros C, SánchezFlor Alfaro V, et al. COVID-19 outbreak in long-term care facilities from Spain. Many lessons to learn. PLoS ONE. 2020;15:e0241030. https://doi.org/10.1371/journal.pone.0241030.

20. Bialek S, Bowen V, Chow N, Curns A, Gierke R, Hall A, et al. Geographic differences in COVID-19 cases, deaths, and incidence-United States, February 12-April 7, 2020. MMWR Morb Mortal Wkly Rep. 2020;69:465-71. https://doi.org/10.15585/ mmwr.mm6915e4.

21. Tarlow B, Gubatan J, Khan MA, Cholankeril G. Are proton pump inhibitors contributing to SARS-COV-2 infection? Am J Gastroenterol. 2020;115:1920-1. https://doi.org/10.14309/ajg.00000 00000000933.

22. Vila-Corcoles A, Satue-Gracia E, Ochoa-Gondar O, TorrenteFraga C, Gomez-Bertomeu F, Vila-Rovira A, et al. Use of distinct anti-hypertensive drugs and risk for COVID-19 among hypertensive people: a population-based cohort study in Southern Catalonia. Spain J Clin Hypertens. 2020;22:1379-88. https://doi.org/ 10.1111/jch.13948.

23. Argenzian MG, Bruc SL, Slate CL, Tia JR, Baldwi MR, Barr RG, et al. Characterization and clinical course of 1000 patients with coronavirus disease 2019 in New York: retrospective case series. BMJ. 2020. https://doi.org/10.1136/bmj.m1996.

24. Pranata R, Permana H, Huang I, Lim MA, Soetedjo NNM, Supriyadi $R$, et al. The use of renin angiotensin system inhibitor on mortality in patients with coronavirus disease 2019 (COVID-19): a systematic review and meta-analysis. Diabetes Metab Syndr Clin Res Rev. 2020;14:983-90. https://doi.org/10.1016/j.dsx.2020.06. 047.

25. Lukito AA, Pranata R, Henrina J, Lim MA, Lawrensia S, Suastika $\mathrm{K}$. The Effect of metformin consumption on mortality in hospitalized COVID-19 patients: a systematic review and meta-analysis. Diabetes Metab Syndr Clin Res Rev. 2020;14:2177-83. https:// doi.org/10.1016/j.dsx.2020.11.006.

26. Shea BJ, Reeves BC, Wells G, Thuku M, Hamel C, Moran J, et al. AMSTAR 2: A critical appraisal tool for systematic reviews that include randomised or non-randomised studies of healthcare interventions, or both. BMJ. 2017. https://doi.org/10.1136/bmj. j4008.

27. Bramer WM, Rethlefsen ML, Kleijnen J, Franco OH. Optimal database combinations for literature searches in systematic reviews: a prospective exploratory study. Syst Rev. 2017. https:// doi.org/10.1186/s13643-017-0644-y.

28. Gusenbauer M, Haddaway NR. Which academic search systems are suitable for systematic reviews or meta-analyses? Evaluating retrieval qualities of Google Scholar, PubMed, and 26 other resources. Res Synth Methods. 2020;11:181-217. https://doi.org/ 10.1002/jrsm. 1378 .
29. Darnell MER, Subbarao K, Feinstone SM, Taylor DR. Inactivation of the coronavirus that induces severe acute respiratory syndrome. SARS-CoV J Virol Methods. 2004;121:85-91. https://doi.org/10. 1016/j.jviromet.2004.06.006.

30. Hamming I, Timens W, Bulthuis MLC, Lely AT, Navis GJ, van Goor H. Tissue distribution of ACE2 protein, the functional receptor for SARS coronavirus. A first step in understanding SARS pathogenesis. J Pathol. 2004;203:631-7. https://doi.org/10.1002/ path. 1570 .

31. Lamers MM, Beumer J, Van Der Vaart J, Knoops K, Puschhof $\mathrm{J}$, Breugem TI, et al. SARS-CoV-2 productively infects human gut enterocytes. Science (80-). 2020;369:50-4. https://doi.org/ 10.1126/science.abc1669.

32. Xiao F, Tang M, Zheng X, Liu Y, Li X, Shan H. Evidence for gastrointestinal infection of SARS-CoV-2. Gastroenterology. 2020;158:1831-3. https://doi.org/10.1053/j.gastro.2020.02.055 (e3).

33. Corsonello A, Lattanzio F, Bustacchini S, Garasto S, Cozza A, Schepisi R, et al. Adverse events of proton pump inhibitors: potential mechanisms. Curr Drug Metab. 2017;19:142-54. https://doi. org/10.2174/1389200219666171207125351.

34. Namazi MR, Jowkar F. A succinct review of the general and immunological pharmacologic effects of proton pump inhibitors. J Clin Pharm Ther. 2008;33:215-7. https://doi.org/10.1111/j.13652710.2008.00907.x.

35. Qiu T, Zhou J, Zhang C. Acid-suppressive drugs and risk of kidney disease: a systematic review and meta-analysis. J Gastroenterol Hepatol. 2018;33:1566-73. https://doi.org/10.1111/jgh. 14157.

36. Xie Y, Bowe B, Li T, Xian H, Balasubramanian S, Al-Aly Z. Proton pump inhibitors and risk of incident $\mathrm{CKD}$ and progression to ESRD. J Am Soc Nephrol. 2016;27:3153-63. https://doi.org/10. 1681/ASN.2015121377.

37. Xie Y, Bowe B, Li T, Xian H, Yan Y, Al-Aly Z. Long-term kidney outcomes among users of proton pump inhibitors without intervening acute kidney injury. Kidney Int. 2017;91:1482-94. https:// doi.org/10.1016/j.kint.2016.12.021.

38. Pranata R, Supriyadi R, Huang I, Permana H, Lim MA, Yonas $\mathrm{E}$, et al. The association between chronic kidney disease and new onset renal replacement therapy on the outcome of COVID-19 patients: a meta-analysis. Clin Med Insights Circ Respir Pulm Med. 2020;14:1179548420959165. https://doi.org/10.1177/11795 48420959165.

39. Lim MA, Pranata R, Huang I, Yonas E, Soeroto AY, Supriyadi R. Multiorgan failure with emphasis on acute kidney injury and severity of COVID-19: systematic review and meta-analysis. Can J Kidney Heal Dis. 2020;7:205435812093857. https://doi.org/10. $1177 / 2054358120938573$.

40. Andhika R, Huang I, Wijaya I. Severity of COVID-19 in endstage kidney disease patients on chronic dialysis. Ther Apher Dial. 2020. https://doi.org/10.1111/1744-9987.13597.

Publisher's Note Springer Nature remains neutral with regard to jurisdictional claims in published maps and institutional affiliations. 